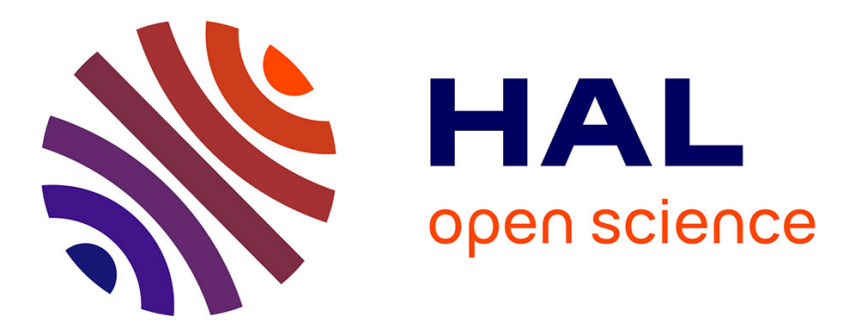

\title{
Inflation Targeting under Heterogeneous Information and Sticky Prices
}

\author{
Cheick Kader M'Baye
}

\section{To cite this version:}

Cheick Kader M'Baye. Inflation Targeting under Heterogeneous Information and Sticky Prices. 2012. halshs-00677671

\section{HAL Id: halshs-00677671 \\ https://shs.hal.science/halshs-00677671}

Preprint submitted on 9 Mar 2012

HAL is a multi-disciplinary open access archive for the deposit and dissemination of scientific research documents, whether they are published or not. The documents may come from teaching and research institutions in France or abroad, or from public or private research centers.
L'archive ouverte pluridisciplinaire HAL, est destinée au dépôt et à la diffusion de documents scientifiques de niveau recherche, publiés ou non, émanant des établissements d'enseignement et de recherche français ou étrangers, des laboratoires publics ou privés. 
Inflation Targeting under Heterogeneous Information and Sticky Prices

Cheick Kader M'baye

Mars 2012 


\section{GATE Groupe d'Analyse et de Théorie Économique Lyon-St Étienne}

93, chemin des Mouilles 69130 Ecully - France

Tel. +33(0)4 72866060

Fax $+33(0) 472866090$

6, rue Basse des Rives 42023 Saint-Etienne cedex 02 - France

Tel. +33 (0)4 77421960

Fax. +33 (0)4 77421950

Messagerie électronique / Email : gate@gate.cnrs.fr

Téléchargement / Download : http://www.gate.cnrs.fr - Publications / Working Papers 


\title{
Inflation Targeting under Heterogeneous Information and Sticky Prices*
}

\author{
Cheick Kader M'baye ${ }^{\dagger}$
}

December 13, 2011

\begin{abstract}
Under what conditions should a central bank adopt an inflation targeting regime? This is the main question we address in this paper. A large part of the literature puts forward that these regimes should have to be adopted, as they yield higher macroeconomic performances. We analyze the issue of optimal inflation targeting in a new theoretical framework, which conciliates the interaction between the degree of price stickiness, and the degree of strategic complementarities in firms' price setting. We show that adopting a target for inflation, crucially depends on the sequential but complementary importance of the model's parameters. In particular, we show that strategic complementarities appear to be the first driving force. When they are low, the central bank must adopt an inflation targeting regime whatever the importance of other parameters in the model. By contrast, when the degree of strategic complementarities is high, adopting a target for inflation depends on both the degree of price stickiness and the precision of central bank's information about
\end{abstract}

*This paper has been written when I was visiting the School of Public Policy (SPP) of George Mason University (Washington, USA). I am particularly grateful to professors Andrew Hughes Hallett, Camille Cornand, and Jean Pierre Allegret for their useful comments, as well as all participants at SPP and GATE-LSE seminars. All remaining errors are my own.

${ }^{\dagger}$ Université de Lyon, Lyon, F-69007, France; Université Lyon 2, Lyon, F-69007, France; Ecole Normale Supérieure de Lyon, Lyon, F-69007, France; CNRS, GATE Lyon St Etienne, Ecully, F-69130, France. Email: mbaye@gate.cnrs.fr. 
the fundamentals of the economy. When prices are flexible enough, adopting an inflation target is never optimal. However, when prices are strongly sticky, and the central bank holds precise information about the fundamentals, the central bank should adopt an explicit target for inflation.

JEL Classification : E52; E58; E61; E31.

Keywords : Inflation targeting, price stickiness, heterogeneous information, strategic complementarities.

\section{Introduction}

One of the major observed trends in the practice of central banks over the last two decades is their evolution towards greater transparency. This shift from their traditional secrecy to greater transparency concerns all types of regimes that central banks adopted.

Geraats [10] defines transparency as the absence of any asymmetric information between the central bank and the private sector ${ }^{1}$. Under transparency, both the central bank and the private sector share the same information and face the same uncertainty about the economy. In this new and influential practice of monetary policy, inflation targeting central banks emerge on average as the most transparent central banks ${ }^{2}$.

Inflation targeting regime has aroused a great interest in modern monetary policy, and has been adopted by more than twenty developed and developing countries. The reasons commonly put forward in the literature, are the fact that these regimes yield the greatest macroeconomic performances. Yet, a part of the literature on inflation targeting including Friedman and Kuttner [9] criticizes this monetary regime arguing that, it cares more about inflation stabilization and therefore, leads to greater output variability which may be harmful to social welfare. Do these regimes really matter in terms of global welfare, and under what conditions should a central bank explicitly announce a target

\footnotetext{
${ }^{1}$ Geraats also identifies five aspects of central banks' transparency which are briefly: political transparency (about policy objectives and targets), economic transparency (about forecasts and used models), policy transparency (about decisions and future policy inclination), procedural transparency (about strategy and voting) and operational transparency (about policy implementation and control errors).
}

${ }^{2}$ See Geraats [11] for more details about the trends in central banks' transparency. 
for inflation? The aim of this paper is precisely to analyze the welfare implications of adopting an inflation target in a new keynesian's sticky prices framework à la Calvo [5], when the economy is characterized by heterogeneous information among firms and strategic complementarities in price setting. Our approach focuses on the impact of the interaction between both sticky prices and strategic complementarities, to assess whether a central bank must optimally implement an inflation targeting as a framework for its monetary policy. To the best of our knowledge, this paper is the first to explicitly analyze welfare effects of inflation targeting regimes in such a theoretical setup.

Our motivation to analyze inflation targeting in such a framework is justified by the following observations.

First, the literature in monetary theory has shown that monetary policy has real effects on the short run's economic activity, and puts forward two main arguments to explain these real short run effects. The first argument in the line of Phelps [18] and Lucas [16], explains this phenomenon by the fact that economic agents have heterogeneous and imperfect information about the state of the economy, while the second argument in the spirit of Taylor [26] and Calvo [5], stresses rigidities in the adjustment of prices or wages to explain these real effects. The argument of distortion due to heterogeneous and imperfect information has been criticized in the empirical literature, because it does not explain the persistence of fluctuations observed in the business cycle despite the quite rapid availability of perfect information about macro data. Therefore, the second part of the literature argues that these short-term real effects are mainly explained by the presence of rigidities in prices or wages' adjustment. Bils and Klenow [4] have also empirically shown how relevant sticky prices are. Consequently, taking into account both distortions in a monetary policy model can help matching both theoretical and empirical conclusions.

The second underlying observation is that, in most interesting economies including a monopolistic market environment, the optimal decision of an agent depends on the actions of others. Indeed, when the market is subject to imperfect competition, a firm will have to raise its price when it expects the other firms to do so. By increasing its price without considering the actions of other firms, it will lose market shares. So a firm makes its price setting decision not only according to its own expectations about the fundamentals, but also its expectations about what other firms will do based on all its available information. 
It turns out that strategic complementarities matter.

The presence of both frictions (price stickiness and heterogeneous information among firms) makes inflation too costly to social welfare in the sense that it increases price dispersion across firms, and when prices are strategic complements, both frictions lead to larger dispersion in prices which is inevitably detrimental to welfare as it amplifies the cost of inflation. By releasing information that is common knowledge to all firms especially information about its target for inflation, the central bank may help reducing forecasts errors and price dispersion across firms by providing a focal point to agents' expectations. These considerations might therefore justify the adoption of an inflation targeting regime by a central bank.

The rest of the paper is organized in the following way. Section 2 reviews the related literature about inflation targeting, and central banks' transparency. Section 3 presents our model which associates heterogeneous information about the state of the economy and strategic complementarities, as well as Calvo's sticky prices assumption. Section 4 presents and analyzes our results, and section 5 concludes.

\section{Related literature}

Inflation targeting is a recent monetary policy strategy which has been first implemented by the Reserve Bank of New Zeland in 1990, followed by more than twenty developed and developing countries. This monetary policy regime is mainly characterized by a clear announcement by the central bank of its inflation target that is its primary objective, as well as a high degree of transparency and accountability.

In practice, inflation targeting is never strict but always flexible in the sense that central banks that targeting inflation also give some weight to stabilizing the real economy, either implicitly or explicitly (Svensson [23], [25]). So, the objective of a flexible inflation targeting central bank is to minimize the gaps between current inflation and the target, as well as putting some weight to stabilize the output gap ${ }^{3}$. A large empirical literature including Roger and Stone [20], and Levin et al. [15] finds positive effects of the inflation target on the variability of inflation and output, in the countries that adopted inflation

\footnotetext{
${ }^{3}$ The gap between current output and the long-run flexible output.
} 
targeting. Demertzis and Viegi [7] and [8], argue that one of the main advantages in adopting a target for inflation is that, it serves as a focal point for agents' inflation expectations $^{4}$. In the case of UK, King [14] shows that inflation expectations of agents have been effectively anchored to the Bank of England's inflation target. The success of inflation targeting is therefore generally approved in monetary theory, and no country has abandoned this monetary policy after adopting it except to join a monetary union (Svensson [25]). As noted earlier, inflation targeting central banks are on average the most transparent central banks. The fact that a central bank announces its target for inflation, is typically a kind of transparency in itself.

The literature about central bank's transparency has grown up quickly, and is usually in favor of transparency. Transparency reduces uncertainty between the central bank and the private sector about the economy's statement, and can therefore improve monetary policy efficiency (Geraats [10]). Demertzis and Hughes Hallett [6] pointed out that the increase in central bank transparency decreases the volatility of inflation and output, even though their average levels have not been affected.

Recently however and following the influential work of Morris and Shin [17], a particular issue has been raised about the welfare implications of disclosing more and better public information to the private sector. The latter authors argue that in an environment characterized by strategic complementarities and agents having heterogeneous information about the fundamentals, more precise public information can be harmful to social welfare in the sense that, private agents put too large attention to this information compared to its real value. Consequently, agents overreact to public information and make the economy more sensitive to inevitable forecasts errors in the public information. This overreaction would be an increasing function of strategic complementarities. Their argu-

\footnotetext{
${ }^{4}$ These authors analyze how an inflation target serves as a focal point for agents' expectations, when the central bank may lack credibility. Particularly they found that an explicit inflation target may provide agents with better anchors for coordinating their expectations in the case where no great shock affects the economy, or where all other available public information is very unclear, letting the inflation target as the only clear public information. While these authors focus their analysis on the coordinating effect of an inflation target, our analysis mainly focuses on the welfare implications of adopting an inflation target when the central bank is sufficiently credible, by providing the conditions under which this regime should be adopted.
} 
ment has received a special attention in the academic literature. Some authors including Svensson [24] and Woodford [30], have challenged Morris and Shin's result by scrutinizing their own model and conclude that their argument is actually in favor of transparency. Hellwig [12] and Roca [19] have shown in fully micro-founded frameworks, that releasing more accurate public information is welfare increasing. While the literature in the spirit of Morris and Shin [17] assesses the welfare effects of transparency when the role of the central bank is just releasing or withholding information, James and Lawler [13] modified the basic framework of Morris and Shin, by providing a setting which jointly accounts for the communication and action of the central bank. They found that more precise public information unambiguously decreases social welfare.

The welfare effects of transparency in an environment which takes into account both the action and communication of the central bank, have also been addressed in relevant monetary policy models. For instance, Walsh [28] argues that when the role of the monetary authority is both to stabilize the economy through its instrument, as well as releasing information, transparency provides more precise information to firms, but at the same time makes their decisions more sensitive to the central bank's forecast errors. Consequently, inflation may become more volatile when the central bank announces its policy targets $^{5}$. Baeriswyl and Cornand [2] point out that the welfare effects of transparency, depend on how public information interacts with the policy action. They found that providing firms with more public information by directly making announcements is harmful to price dispersion, because it impairs the trade-off the central bank faces between the output gap and price dispersion. By contrast, the information conveyed by the monetary instrument is welfare improving when firms' coordination is highly valuable.

\section{The economy}

In this section, we present the features of the Calvo's sticky prices model, that is combined with the assumption that agents have heterogeneous private information about the state of the economy. The basis of the model is the same as in Angeletos and La'O [1]. However, we extend the model by deriving the inflation expectations made by adjusting price agents,

\footnotetext{
${ }^{5}$ Hence, his argument supports Morris and Shin's.
} 
and allow for monetary authority's intervention. While these authors mainly care about higher order expectations to explain price inertia, our analysis focuses exclusively on the welfare consequences of adopting an explicit target for inflation as a framework for monetary policy. Furthermore, the informational structure of our model is fundamentaly different from the latter paper.

Our setting is close to Walsh [28]' framework in the sense that he also considers both frictions (price stickiness and heterogeneous information among agents) in his transparency effects' analysis. However, his approach does not explicitly account for the impact of the interaction of both strategic complementarities and sticky prices on the choice facing the central bank in its policy strategy, nor taking into account an explicit target for inflation in the welfare function. Our approach is also different from Baeriswyl and Cornand [2] as these authors analyze welfare effects of transparency in a flexible price model. Moreover, their analysis of transparency focuses on the impact of economic transparency, while the analysis presented in this paper highlights the impact of political transparency (inflation target) on social welfare. Nevertheless as in Walsh, and Baeriswyl and Cornand, we consider that the monetary instrument has a dual role. It serves not only as an action to stabilize the economy, but also provides indirectly to firms, the central bank's estimation about the state of the economy.

The economy is characterized by a representative household, a continuum of monopolistic competitive firms, and a central bank. The central bank of the economy is the sole source of public information, and has developed a credible reputation in achieving low and stable inflation. Moreover, it partially controls the nominal aggregate output through its monetary instrument, and seeks to maximize the utility function of the representative household, as well as keeping inflation within its band's target ${ }^{6}$. In addition, we allow the economy to be hit by two types of stochastic shocks that are a mark-up shock and a demand shock. We first present the features of the representative household maximizing its utility function according to its budget constraint. Then we present the problem the firms face and therefore their price setting behavior, and finally we present the monetary policy's side of the economy. Throughout the paper, the lower case letters denote log

\footnotetext{
${ }^{6}$ This assumption will be explained later in the text.
} 
deviations from steady state values of the variable denoted by the corresponding capital letter.

\subsection{The representative household}

The household chooses his consumption level and labor supply, to maximize its utility function subject to its budget constraint ${ }^{7}$. His utility function is then given by:

$$
\sum_{t=0}^{\infty} \beta^{t} U\left(C_{t}, N_{t}\right)
$$

with :

$$
U\left(C_{t}, N_{t}\right)=\log C_{t}-N_{t}
$$

where $N_{t}$ is the labor supplied by the household, and $\beta \in(0,1)$ is the discount factor. The aggregate consumption is given by the standard Dixit-Stiglitz aggregator :

$$
C_{t}=\left[\int_{0}^{1} C_{i},^{\frac{\theta-1}{\theta}} d i\right]^{\frac{\theta}{\theta-1}},
$$

where $C_{i, t}$ is the differentiated good produced by firm $i$, and $\theta>1$ is the elasticity of substitution between differentiated goods. The lower this elasticity, the more firms can increase their prices and hence, their mark-up stemming from their market power as goods become less substitutable.

Modern macroeconomic theory usually assumes that this elasticity is constant for all differentiated goods. However and following Steinsson [21], we assume that $\theta$ is changing throughout time. One can interpret this assumption by the fact that the variety of products produced in the economy as well as their substitutability are constantly changing. It turns out that the resulting monopoly power and hence, the desired mark-up of firms also vary throughtout time. This assumption will be helpful by allowing us to introduce a

\footnotetext{
${ }^{7}$ For simplicity, we focus here on commodities market and abstract from capital accumulation and assets market, so that there is no saving at equilibrium. One could argue that this is a restriction, because assets market is the most concerned about monetary policy. We will not argue against this restriction but we solely consider commodities market because our purpose in this paper is to focus on the effects of monetary policy (inflation target) on the price setting behavior of firms.
} 
mark-up shock in the model. Given the aggregate consumption, the household's demand for consumption between differentiated goods of firms follows the rule :

$$
C_{i, t}=\left(\frac{P_{i, t}}{P_{t}}\right)^{-\theta} C_{t},
$$

where $P_{t}=\left[\int_{0}^{1} P_{i},{ }_{t}^{1-\theta} d i\right]^{\frac{1}{1-\theta}}$ is the aggregate price index.

\subsection{Firms and price setting behavior}

Each firm $i$ produces its differentiated good's output according to the following function :

$$
Y_{i, t}=A_{i, t} N_{i, t}^{\eta}
$$

where $A_{i, t}$ is the specific productivity disturbance of firm $i, N_{i, t}$ the labor supplied by the household to firm $i$, and $\eta \in(0,1)$ denotes the degree of diminishing returns in production. The ressource constraint implies that $Y_{i, t}=C_{i, t}$ for all $i$ and hence aggregate output is given by $Y_{t}=C_{t}$. It follows that the nominal aggregate output is then given by :

$$
D=P_{t} C_{t}
$$

where $D$ is the level of nominal aggregate output that the central bank tries to control with its monetary instrument. Assume that prices are flexible, and current nominal output is common knowledge when firms decide to set prices. It follows that the optimal price setting by firm $i$ at time $t$ is given by :

$$
p_{i, t}^{*}=\phi+m c_{i, t},
$$

where $\phi=\frac{\theta}{\theta-1}$ is the monopolistic mark-up, and $m c_{i, t}$ is firm $i$ 's nominal marginal cost at the end of the period and is given by :

$$
m c_{i, t}=w_{t}+\frac{\eta-1}{\eta} y_{i, t}-\frac{1}{\eta} a_{i, t},
$$

where $w_{t}$ is the nominal competitive wage rate. Household's optimal condition for work implies that :

$$
w_{t}-p_{t}=c_{t}
$$


From (3) :

$$
c_{i, t}-c_{t}=-\theta\left(p_{i, t}-p_{t}\right) .
$$

Market clearing conditions require that : $c_{i, t}=y_{i, t}$, and $c_{t}=y_{t}$. Finally from (5), one gets the expression of real aggregate output relative to its steady state value (normalized here to 0$)^{8}$ :

$$
y_{t}=d_{t}-p_{t}
$$

where $d_{t}$ denotes the log expression of nominal aggregate output. Combining these conditions provides the optimal flexible price of firm $i$ at $t$ :

$$
p_{i, t}^{*}=(1-k) d_{t}+k p_{t}+u_{i, t},
$$

where $k=1-\frac{1}{\eta+(1-\eta) \theta} \in(0,1)$ defines the degree of strategic complementarities in pricing decisions, and where :

$$
u_{i, t}=\frac{\eta}{\eta+(1-\eta) \theta} \phi-\frac{1}{\eta+(1-\eta) \theta} a_{i, t}
$$

is an error term representing a linear combination of firms' mark-up and productivity disturbance. As we said earlier, the assumption of stochastic elacticity of substitution among goods allows us to consider a mark-up shock into our model. The mark-up shock in the model is thus mainly caused by the fluctuations in this elasticity. It is well known in the literature that these shocks generate a trade-off between stabilizing output and inflation, and then, cannot be offset by the central bank ${ }^{9}$. To keep the analysis as simple as possible, we consider solely the mark-up and normalize the error term $u_{i, t}$, letting it to be log-normally distributed across firms, and to generate an aggregate mark-up shock with mean zero :

$$
u \sim N\left(0, \sigma_{u}^{2}\right)
$$

Firms will then have to consider their expectations about the realization of the aggregate mark-up shock in their pricing decisions. Under the flexible prices assumption, all firms

\footnotetext{
${ }^{8}$ Hence, this is also our mesure of the real output gap.

${ }^{9}$ In the presence of both mark-up and demand shocks, the central bank offsets the demand shock, and leans against the wind in response to mark-up shock according to the precision of its signals on these shocks (see Baeriswyl and Cornand [2]).
} 
will set the same optimal price as in (11). However, following Calvo [5], we postulate that at every period $t$, only a fraction $(1-\omega)$ of firms can adjust their prices, while the remaining fraction $\omega$ of firms keep their prices constant $(\omega \in(0,1))$. If firm $i$ can adjust its price at time $t$, the price it will set is equal to its current expectation of the weighted average of the current and all future prices, conditional on all its current available information :

$$
p_{i, t}=E_{i, t}\left[(1-\beta \omega) \sum_{j=0}^{\infty}(\beta \omega)^{j} p_{t+j}^{*}\right]
$$

where $E_{i, t}$ denotes the expectations based on information available to firm $i$ at period t. By combining (11) and (12), one gets the optimal price set by a firm having the opportunity to adjust its price at $t$ :

$$
p_{i, t}^{*}=(1-\beta \omega) \sum_{j=0}^{\infty}(\beta \omega)^{j}\left[(1-k) E_{i, t} d_{t+j}+k E_{i, t} p_{t+j}+E_{i, t} u_{t+j}\right] .
$$

Note that before adjusting its price, the firm observes neither the aggregate price level nor the nominal aggregate demand and the aggregate mark-up shock. The adjusting firms will set different prices because their expectations are based on different information sets. Re-writing (13) recursively yields :

$$
p_{i, t}^{*}=(1-\beta \omega) E_{i, t}\left[(1-k) d_{t}+k p_{t}+u_{t}\right]+(\beta \omega) E_{i, t} p_{i, t+1}^{*} .
$$

Let $\pi_{i, t}^{*}=p_{i, t}^{*}-p_{t-1}$ be the inflation generated by adjusting firm $i$, where $p_{t-1}$ denotes the last period's aggregate log price level. Let $\bar{\pi}_{t}^{*}$ be the average inflation across the adjusting firms at time $t$, and $\pi_{t}$ be the current aggregate inflation rate. The current aggregate price level is given by :

$$
p_{t}=(1-\omega) \overline{p_{t}^{*}}+\omega p_{t-1},
$$

where $\overline{p_{t}^{*}}=\int_{0}^{1} p_{i}^{*}, t$. Hence, $(15)$ implies that $\overline{p_{t}^{*}}-p_{t}=\omega\left(\overline{p_{t}^{*}}-p_{t-1}\right)$ and that :

$$
\pi_{t}=p_{t}-p_{t-1}=(1-\omega)\left(\overline{p_{t}^{*}}-p_{t-1}\right)=\left(\frac{1-\omega}{\omega}\right)\left(\overline{p_{t}^{*}}-p_{t}\right) .
$$

Assuming that all current information is observed at the end of each period $t$ implies that each adjusting firm in $t+1$ will set the same price as other adjusting firms. Hence we have $E_{i, t} p_{i, t+1}^{*}=E_{i, t} p_{t+1}^{*}$. 
By combining (14),(16) and the definition of $\pi_{i}^{*}, t$, one gets after some manipulation :

$$
\pi_{i, t}^{*}=k(1-\omega) E_{i, t} \bar{\pi}_{t}^{*}+(1-\beta \omega) E_{i, t}\left[(1-k) d_{t}+u_{t}\right]+\left(\frac{\beta \omega}{1-\omega}\right) E_{i, t} \pi_{t+1},
$$

where $\overline{\pi_{t}^{*}}=\bar{p}_{t}^{*}-p_{t-1}$. According to equation (17), an adjusting firm $i$ will base its price decision on its expectations about what other adjusting firms are choosing (hence on average inflation), its expectations about current nominal aggregate output and on mark-up shock, as well as its expectations about the future current inflation.

\subsection{The features of monetary policy and the nominal aggregate output}

We now turn to the features of monetary policy in our model. The monetary authority is represented by a central bank which maximizes the utility function of the representative household by means of its monetary instrument :

$$
\max \sum_{t=0}^{\infty} \beta^{t} U\left(C_{t}, N_{t}\right) .
$$

Woodford [29] has derived the second order approximation of the household's utility in a fully microfounded Calvo model, and has shown that this utility function is consistent with the standard quadratic loss-function of the form :

$$
E\left(L_{t}\right)=\frac{1}{2}\left[\lambda\left(y_{t}-y_{t}^{*}\right)^{2}+\pi_{t}^{2}\right]
$$

where $y_{t}^{*}$ is the central bank's efficient level of output gap, and $\lambda \in(0,1)$ denotes the weight the central bank attributes to output gap stabilization. Note that this loss function explicitly takes the efficient level of output gap as a target, and implicitly takes zero as the target for inflation. The presence of $y_{t}^{*}$ in the loss function means that the central has an incentive to push output above its natural level, creating an inflation bias à la BarroGordon [3]. However, there is no such incentive in our setup. As stressed by Svensson [22], it is a general consensus that inflation targeting central banks do not normally have any ambitious output target that exceeds the potential output ${ }^{10}$. Otherwise, the assumption

\footnotetext{
${ }^{10}$ Hence, the central bank's output target is not subject to choice, but is simply given by the capacity level of production.
} 
of zero inflation target is not realistic in the short-run. Although under credible inflation targeting the long-run inflation target is zero as pointed by Walsh [27], the simultaneous presence of frictions such as price stickiness and heterogeneous information, gives rationale for a non-zero inflation target in the short-run. Hence, we modify the above loss-function by setting $y_{t}^{*}=0$, and allowing for a non-zero inflation target :

$$
E\left(L_{t}\right)=\frac{1}{2} E\left[\lambda y_{t}^{2}+\left(\pi_{t}-\pi^{*}\right)^{2}\right] .
$$

Equation (18) thus represents the standard period loss function of an inflation targeting central bank. Inflation is stabilized around its target value $\pi^{*}$, while output is stabilized around its natural level.

However, we are interested in an inflation targeting central bank that has an inflation band target. In other words, the central bank considered here has the objective to keep current inflation within a band target ${ }^{11}$. Such an argument is usually put forward to explain the need of central bank's flexibility, on achieving other macroeconomic variables' stability in an incertain environment. Let $\left[\pi_{1}, \pi_{2}\right]$ be the interval of that band with $\pi_{2}>\pi_{1}$. Let $\pi_{1}=\pi^{*}-\rho$, and $\pi_{2}=\pi^{*}+\rho$ be the boundaries of the band with $\pi^{*}$ denoting the mid-point of the band, and $\rho$ normally distributed : $\rho \sim N\left(0, \sigma_{\rho}^{2}\right)$.

This specification of the band target means that the width of the band may change over time for instance, due to economic conditions. However, firms don't know precisely where the monetary authority wishes to stabilize inflation within the band, but are aware that they have to focus their attention on this band target. When the central bank does not explicitly announce its band target to the public, firms face complete uncertainty about the intention of the central bank in stabilizing inflation, and only focus on their private information in assessing the economy.

Considering inflation being inside this defined band target in the loss function implies that (18) changes to the following form:

$$
E\left(L_{t}\right)=\frac{1}{2} E\left[\lambda y_{t}^{2}+2\left(\pi_{t}-\pi^{*}\right)^{2}+2 \rho^{2}\right]
$$

To make things simpler later on and in order to highlight the deviations of inflation from

\footnotetext{
${ }^{11}$ In practice, most of the inflation targeting central banks prefer a band rather than a point target in their design of the policy objective.
} 
both boundaries of the band, we re-write (19) as:

$$
E\left(L_{t}\right)=\frac{1}{2} E\left[\lambda\left(y_{t}\right)^{2}+\left(\pi_{1}-\pi_{t}\right)^{2}+\left(\pi_{2}-\pi_{t}\right)^{2}\right] .
$$

The central bank then faces two options in choosing its monetary policy strategy: either to adopt an inflation targeting regime, or to be a non-inflation targeter. One must note that any central bank has in practice an inflation target it wishes to reach, irrespective of whether it announces it clearly to the public or not. As in Demertzis and Viegi [7], we call a central bank that clearly announces its target for inflation an "inflation targeter", and identify a central bank that does not make an attempt to explicitly communicate its target to the public as a "non-inflation targeter". Let $I$ be the central bank's instrument with which it minimizes its per-period loss-function, as well as controls partially the nominal aggregate output. The monetary transmission mechanism from $I$ to the nominal aggregate output is given by :

$$
d_{t}=I+v_{t}
$$

with $v_{t}$ a demand disturbance normally distributed :

$$
v_{t} \sim N\left(0, \sigma_{v}^{2}\right)
$$

\subsection{Informational structure of the economy}

Two aggregate shocks hit the economy: the mark-up shock $u_{t}$, and the demand shock $v_{t}$. Each of these shocks is serially and mutually uncorrelated, and both the central bank and firms act before observing the current values of these shocks. They receive however idiosyncratic signals about these shocks before for the central bank to set its instrument, and for adjusting firms to set prices. The central bank receives private signals about mark-up and demand shocks, which allows it to estimate the true realization of these shocks before setting its instrument. These private signals are centered on the real values of the shocks with some error terms normally, identically and independently distributed :

$$
\begin{gathered}
u_{c b, t}=u_{t}+\varepsilon_{c b, t} \\
v_{c b, t}=v_{t}+s_{t},
\end{gathered}
$$


where $\varepsilon_{c b} \sim N\left(0, \sigma_{\varepsilon}^{2}\right)$ and $s_{t} \sim N\left(0, \sigma_{s}^{2}\right)$.

The instrument of the central bank is adjusted in a manner consistent with keeping current inflation within the band target. Hence, the instrument the central bank will set is a linear combination of its private signals on shocks, as well as its inflation target ${ }^{12}$ :

$$
I=\alpha_{1} u_{c b}+\alpha_{2} v_{c b}+\alpha_{3} \pi_{2}
$$

where $\alpha_{1}, \alpha_{2}$ and $\alpha_{3}$ represent respectively optimal monetary coefficients the central bank chooses in response to the mark-up shock, the demand shock, as well as optimal adjustment to achieve its target.

On the other side, each firm $i$ also gets a private signal on the mark-up shock. This signal is private information to firm $i$ in the sense that, it is unobserved by any other firm. So, individual firms have potentially different information about the shock. This private signal is centered on the true value of the mark-up shock, with an error term normally, identically and independently distributed among firms :

$$
u_{i t}=u_{t}+\varepsilon_{i t}
$$

with :

$$
\varepsilon_{i t} \sim N\left(0, \sigma_{\varepsilon i}^{2}\right)
$$

\subsection{Sequence of events}

The game is structured as follows. First, the central bank perfectly knows the inflation band target it has to reach. The reaction of its monetary instrument partially depends on this target. Two shocks hit the economy. The central bank receives private signals about these shocks, and takes them into account before setting its instrument. The instrument depends not only on the target for inflation, but also on the signals of the central bank on the aggregate mark-up and demand disturbances. The central bank then sets its instrument and makes it observable by firms. Firms also receive a private signal on mark-up shock. In addition, they observe the monetary instrument and are aware

\footnotetext{
${ }^{12}$ As the central bank adjusts its instrument with respect to both $\pi_{1}$ and $\pi_{2}$ with the same coefficient $\alpha_{3}$, it is convenient to consider just one boundary of the band in the instrument so as to avoid redundance. Here we consider $\pi_{2}$.
} 
that via this instrument, the central bank optimally responds to aggregate disturbances with respect to its private signals, but also has the objective to keep current inflation within its target. So, firms are aware that this instrument depends on the central bank's target for inflation, as well as its signals about the macroeconomic disturbances. However, without any explicit announcement of the central bank about its target and/or its private signals about the shocks, firms cannot perfectly infer the central bank's target or its signals on shocks. Indeed, the movements of the instrument will be ambiguous for them unless they have more information about that. Thus, according to their private signal about the mark-up shock, the monetary instrument and any other information the central bank may disclose, the adjusting firms rationally set their prices and form their inflation expectations. Finally households supply labor, demand products for consumption and production takes place.

\section{Optimal monetary policy}

In this section, we analyze the welfare implications of adopting an inflation target within our model. To do so, we first present the equilibrium strategy of adjusting firms under non-inflation and inflation targeting respectively, as well as the welfare losses that stem from both regimes. Secondly, we compare these welfare losses for different alternatives of the parameters of our model. The interaction of both strategic complementarities and sticky prices, will then allow us to derive implications for optimal monetary policy.

\subsection{Optimal policy under non-inflation targeting regime}

We first present the equilibrium strategy of adjusting firms, and secondly the expected loss function of such a regime.

\subsubsection{Equilibrium strategy}

If the central bank is a "non-inflation targeter", the only public information firms face before setting their prices is the monetary instrument. However as said before, even though firms observe this instrument, without any explicit announcement by the central 
bank, they cannot perfectly infer the information conveyed in this instrument that is, the central bank's target for inflation, as well as its private signals on macroeconomic disturbances. So firms base their optimal choices only on their private signals about the mark-up shock, and the observable instrument. Therefore, the equilibrium strategy of the adjusting firm $i$ is a linear combination of its private information on the mark-up shock, and the central bank's instrument ${ }^{13}$ :

$$
\pi_{i, t}^{*}=\gamma_{1} u_{i, t}+\gamma_{2} I
$$

with :

$$
\begin{gathered}
\gamma_{1}=\frac{(1-\omega \beta)\left[(1-k) O_{21}+O_{11}\right]}{1-k(1-\omega) O_{11}} \\
\gamma_{2}=\frac{-(1-\omega \beta)(1-k)-\left(1-\alpha_{3} \pi^{*}\right)\left[(1-\omega \beta)\left((1-k) O_{22}+O_{12}\right)+k O_{12} \gamma_{1}(1-\omega)\right]}{k(1-\omega)-1} .
\end{gathered}
$$

Aggregating over all adjusting firms and multiplying by $(1-\omega)$, we obtain the current aggregate inflation rate as a linear combination of the actual realization of the mark-up shock, and the policy instrument :

$$
\pi_{t}=(1-\omega) \overline{\pi^{*}}=\tilde{\gamma_{1}} u_{t}+\tilde{\gamma_{2}} I
$$

where $\tilde{\gamma}_{1}=(1-\omega) \gamma_{1}$, and $\tilde{\gamma}_{2}=(1-\omega) \gamma_{2}$.

\subsubsection{Welfare function under non-inflation targeting}

We now return to our central bank's objective function which is to minimize the variance of the output gap, as well as the deviation of current inflation from its band target as in (20):

$$
E\left(L_{t}\right)=\frac{1}{2} E\left[\lambda\left(y_{t}\right)^{2}+\left(\pi_{1}-\pi_{t}\right)^{2}+\left(\pi_{2}-\pi_{t}\right)^{2}\right] .
$$

Let $\varpi_{1}=E\left[\left(\pi_{1}-\pi_{t}\right)^{2}\right]$ be the deviation of current inflation from $\pi_{1}$, and $\varpi_{2}=E\left[\left(\pi_{2}-\pi_{t}\right)^{2}\right]$ the deviation from $\pi_{2}$. Using (23) and expressing these components of inflation variability in terms of the underlying stochastic variables, we obtain :

$$
\varpi_{1}=\left(\alpha_{1} \tilde{\gamma}_{2}+\tilde{\gamma}_{1}\right)^{2} \sigma_{u}^{2}+\left(\alpha_{1} \tilde{\gamma}_{2}\right)^{2} \sigma_{\varepsilon}^{2}+\left(\alpha_{2} \tilde{\gamma}_{2}\right)^{2}\left(\sigma_{v}^{2}+\sigma_{s}^{2}\right)+\left(\alpha_{3}{\tilde{\gamma_{2}}}_{2}+1\right)^{2} \sigma_{\rho}^{2}
$$

\footnotetext{
${ }^{13}$ The details of the calculation are given in the appendix. We follow Morris and Shin (2002) for linear resolution.
} 
and :

$$
\varpi_{2}=\left(\alpha_{1} \tilde{\gamma_{2}}+\tilde{\gamma}_{1}\right)^{2} \sigma_{u}^{2}+\left(\alpha_{1} \tilde{\gamma}_{2}\right)^{2} \sigma_{\varepsilon}^{2}+\left(\alpha_{2} \tilde{\gamma}_{2}\right)^{2}\left(\sigma_{v}^{2}+\sigma_{s}^{2}\right)+\left(\alpha_{3} \tilde{\gamma}_{2}-1\right)^{2} \sigma_{\rho}^{2}
$$

Using (10),(20) and (23), we deduce the variability of the real output gap which yields :

$\operatorname{var}\left(y_{t}\right)=\left[\alpha_{1}\left(1-\tilde{\gamma_{2}}\right)-\tilde{\gamma_{1}}\right]^{2} \sigma_{u}^{2}+\left[\alpha_{1}\left(1-\tilde{\gamma_{2}}\right)\right]^{2} \sigma_{\varepsilon}^{2}+\left[\alpha_{2}\left(1-\tilde{\gamma_{2}}\right)+1\right]^{2} \sigma_{v}^{2}+\left[\alpha_{2}\left(1-\tilde{\gamma_{2}}\right)\right]^{2} \sigma_{s}^{2}+\left[\alpha_{3}\left(1-\tilde{\gamma_{2}}\right)\right]^{2}$

As $\lambda$ is the weight the central bank attributes to output stabilization, $(1-\lambda)$ is the weight the central bank attributes to inflation stabilization. The unconditional expected loss-function of the non-inflation targeting central bank is then given by :

$$
E\left(L_{N I T}\right)=\frac{1}{2}\left[\lambda \operatorname{var}\left(y_{t}\right)+(1-\lambda)\left(\varpi_{1}+\varpi_{2}\right)\right] .
$$

\subsection{Optimal policy under inflation targeting regime}

We proceed here as in the previous subsection. After characterizing the equilibrium strategy of the adjusting firms, we derive the welfare loss function that emerges from this regime.

\subsubsection{Equilibrium strategy}

We now consider that the central bank is an "inflation targeter". As argued earlier, this means that it announces explicitly its band target to the public. The announcement of the central bank's objectives for instance its target for inflation, is a key component of political transparency. We also assume that the central bank discloses its private signal on the demand shock to the public ${ }^{14}$. Thus, not only does the central bank announce its target for inflation, but it also reveals its forecasts on the demand disturbance to the private sector. Inflation targeter therefore increases both political (through the target) and economic (through its signal on the demand shock) transparency in the economy ${ }^{15}$.

\footnotetext{
${ }^{14}$ In practice, inflation targeting central banks are more transparent than non-targeters, and thus not only explicitly announce their inflation targets, but also make great efforts to disclose their forecasts on economic assessment.

${ }^{15}$ Demertzis and Hughes Hallett [6] gather both quantitative targets such as the target for inflation, and the central bank's forecasts as components of economic transparency. However, the analysis presented
} 
This has a crucial implication about the informational structure of the economy. The explicit announcement by the central bank of the target for inflation as well as its signal on the demand shock, will lead to perfect transparency that is, removing any asymmetric information between the central bank and firms. The rationale of this implication is straightforward. As the monetary instrument is a function of both mark-up and demand shocks as well as the target for inflation and is observed by firms, by announcing the inflation target and its signal on the demand shock, the central bank allows firms to perfectly infer its signal on the mark-up shock. So, firms no longer need additional information from the central bank to perfectly understand all information it has about the state of the economy. Therefore, firms will better estimate the actual realization of these shocks in their pricing decisions, and expectations would be better anchored. The optimal decision of adjusting firm $i$ will be a linear combination of all its available information that is, its private signal on the mark-up shock, the target for inflation, the central bank's signal on the demand shock, as well as the observable monetary instrument ${ }^{16}$ :

$$
\pi_{i, t}^{*}=b_{1} u_{i, t}+b_{2} v_{c b}+b_{3} \pi_{2}+b_{4} I
$$

with :

$$
\begin{gathered}
b_{1}=\frac{(1-\omega \beta)\left[(1-k) \Gamma_{21}+\Gamma_{11}\right]}{1-k(1-\omega) \Gamma_{11}}, \\
b_{2}=\frac{-(1-\omega \beta)\left[(1-k) \Gamma_{22}+\Gamma_{12}\right]-k b_{1}(1-\omega) \Gamma_{12}}{k(1-\omega)-1}, \\
b_{3}=\frac{-\left(1-\pi^{*}\right)\left[(1-\omega \beta)\left((1-k) \Gamma_{23}+\Gamma_{13}\right)+k b_{1}(1-\omega) \Gamma_{13}\right]}{k(1-\omega)-1}, \\
b_{4}=\frac{-(1-\omega \beta)(1-k)-\left(1-\alpha_{3} \pi^{*}\right)\left[(1-\omega \beta)\left((1-k) \Gamma_{24}+\Gamma_{14}\right)+k b_{1}(1-\omega) \Gamma_{14}\right]}{k(1-\omega)-1} .
\end{gathered}
$$

in this paper follows Geraats [10] by considering the target for inflation as part of political transparency, and the central bank's signals on the shocks as an aspect of economic transparency.

\footnotetext{
${ }^{16}$ See the appendix for the details of equilibrium calculation.
} 
As before, aggregating over all adjusting firms and multiplying by $(1-\omega)$, yields the current aggregate inflation rate as linear combination of the actual realization of markup shock, central bank's signal on demand shock, the inflation target and the policy instrument :

$$
\pi_{t}=(1-\omega) \overline{\pi_{t}^{*}}=\overline{b_{1}} u_{t}+\overline{b_{2}} v_{c b}+\overline{b_{3}} \pi_{2}+\overline{b_{4}} I
$$

where $\overline{b_{1}}=(1-\omega) b_{1}, \overline{b_{2}}=(1-\omega) b_{2}, \overline{b_{3}}=(1-\omega) b_{3}$, and $\overline{b_{4}}=(1-\omega) b_{4}$.

\subsubsection{Welfare function under inflation targeting}

The method is exactly similar to what has been used for the non-inflation targeter. Let $\Delta_{1}=E\left[\left(\pi_{1}-\pi_{t}\right)^{2}\right]$ be the deviation of current inflation from $\pi_{1}$, and $\Delta_{2}=E\left[\left(\pi_{2}-\pi_{t}\right)^{2}\right]$ the deviation from $\pi_{2}$. By expressing them in terms of stochastic variables using (26), one obtains :

$$
\Delta_{1}=\left(\alpha_{1} \overline{b_{4}}+\overline{b_{1}}\right)^{2} \sigma_{u}^{2}+\left(\alpha_{1} \overline{b_{4}}\right)^{2} \sigma_{\varepsilon}^{2}+\left(\alpha_{2} \overline{b_{4}}+\overline{b_{2}}\right)^{2}\left(\sigma_{v}^{2}+\sigma_{s}^{2}\right)+\left(\alpha_{3} \overline{b_{4}}+\overline{b_{3}}+1\right)^{2} \sigma_{\rho}^{2},
$$

and

$$
\Delta_{2}=\left(\alpha_{1} \overline{b_{4}}+\overline{b_{1}}\right)^{2} \sigma_{u}^{2}+\left(\alpha_{1} \overline{b_{4}}\right)^{2} \sigma_{\varepsilon}^{2}+\left(\alpha_{2} \overline{b_{4}}+\overline{b_{2}}\right)^{2}\left(\sigma_{v}^{2}+\sigma_{s}^{2}\right)+\left(\alpha_{3} \overline{b_{4}}+\overline{b_{3}}-1\right)^{2} \sigma_{\rho}^{2} .
$$

The real output gap variability is given by :

$$
\begin{aligned}
\operatorname{var}_{T}\left(y_{t}\right)= & {\left[\alpha_{1}\left(1-\overline{b_{4}}\right)-\overline{b_{1}}\right]^{2} \sigma_{u}^{2}+\left[\alpha_{1}\left(1-\overline{b_{4}}\right)\right]^{2} \sigma_{\varepsilon}^{2}+\left[\alpha_{2}\left(1-\overline{b_{4}}\right)+1-\overline{b_{2}}\right]^{2} \sigma_{v}^{2} } \\
& +\left[\alpha_{2}\left(1-\overline{b_{4}}\right)-\overline{b_{2}}\right] \sigma_{s}^{2}+\left[\alpha_{3}\left(1-\overline{b_{4}}\right)-\overline{b_{3}}\right]^{2} \sigma_{\rho}^{2}
\end{aligned}
$$

The unconditional expected loss-function of the inflation targeting central bank is therefore given by :

$$
E\left(L_{I T}\right)=\frac{1}{2}\left[\operatorname{var}_{T}\left(y_{t}\right)+(1-\lambda)\left(\Delta_{1}+\Delta_{2}\right)\right]
$$

\subsection{Non-inflation targeting versus inflation targeting regime}

In what follows, we analyze to what extent the central bank must explicitly adopt a target for inflation according to the model we consider. Since we have calculated the loss functions stemming from both policy regimes, we now compare both regimes, by applying a cost-benefit analysis as in Baeriswyl and Cornand [2]. We compare the unconditional 
expected loss of the non-inflation targeting central bank to the expected loss of the inflation targeting central bank. The ratio between the expected loss of the non-inflation targeter and the expected loss of the inflation targeter is then given by:

$$
\frac{E\left(L_{N I T}\right)}{E\left(L_{I T}\right)}
$$

When this ratio is greater than one i.e. $E\left(L_{N I T}\right)>E\left(L_{I T}\right)$, it is optimal for the central bank to be an "inflation targeter".

By contrast, if this ratio is less than one, it is optimal for the central bank to be a "noninflation targeter". We present this ratio to assess the impact of the main parameters driving our model that is, strategic complementarities and price stickiness. To this end, we first present the ratio as a function a price stickiness for three values of strategic complementarities. Then we present the ratio as a function of the precision of firms' private information on mark-up shock, in order to assess its role in the dynamics of the model. Finally, we present the ratio as a function of the precision of the central bank's information about the mark-up shock.

\subsubsection{Interaction between strategic complementarities and sticky prices}

Figure 1 presents the ratio of losses as a function of price stickiness, for three alternative values of strategic complementarities. The result is computed with the following values of the remaining parameters : $\sigma_{u}^{2}=1, \sigma_{v}^{2}=1, \sigma_{\rho}^{2}=1, \sigma_{\varepsilon}^{2}=0.2, \sigma_{\varepsilon i}^{2}=0.2, \sigma_{s}^{2}=0.2$, $\pi^{*}=2, \lambda=0.3$, and $\beta=0.99^{17}$. We concentrate our attention on the extreme values of the parameters, as those are the most interesting cases to study.

Figure 1 shows that strategic complementarities play a fundamental role in the welfare analysis. When the degree of strategic complementarities is low $(k=0.2)$, it is always optimal for the central bank to be an inflation targeter whatever the degree of price stickiness.

The intuition behind this result is the following. When strategic complementarities are low, firms do not really care about the actions taken by other firms in their pricing decisions, and focus on their private information to match the fundamental as well as the central bank's target for inflation. The distortion which may stem from the need to

\footnotetext{
${ }^{17}$ This is the standard value of the discount factor $\beta$, in line with quaterly data.
} 
match the others' choices is therefore removed, and firms focus on achieving central bank's target, as they know that this is the main objective of the central bank. By announcing its primary objective as well as its signal on the demand shock, the central bank allows firms to make better expectations on the mark-up shock, and to anchor these expectations to the credible inflation target. Hence, the central bank reduces its loss by providing to firms a focal point to coordinate their expectations.

However, when strategic complementarities become very high $(k=0.8)$, matching others' actions matters and adds another issue to firms' price setting decisions. In this case, adopting an inflation target depends on the degree of price stickiness. The central bank should opt for an inflation targeting regime only if the degree of price stickiness is very high. The rationale for this result is the following. High degree of strategic complementarities implies that firms act not only to match fundamentals, but also to match the actions of other firms. Therefore, any public announcement made by the central bank will lead to reducing strategic uncertainty about the actions of other firms. In line with the Morris and Shin's effect, firms overreact to the announcements made by the central bank that is, its target for inflation, as well as its signal on the demand shock. Indeed as stressed earlier, both announcements allow firms to perfectly understand the central bank's signal on the mark-up shock, and then exacerbate their response to this mark-up shock. If prices are flexible enough, this behavior will be harmful to social welfare and therefore, adopting an inflation targeting regime is not optimal. Nevertheless, this result does not hold if prices are strongly sticky. Indeed, in this case firms do not exacerbate their response to the mark-up shock, but rather they mainly act according to the past period inflation. The same argument of high strategic complementarities leads firms to mainly base their decisions on past price level behavior, as they expect other adjusting firms to do the same. However, the reaction to the mark-up shock still exists, but its importance is largely reduced by firms' attention to past period price behavior.

Two main effects thus arise from this configuration. The "overreaction effect" due to more information about the mark-up shock ${ }^{18}$, and the "anchoring effect" of the inflation

\footnotetext{
${ }^{18}$ As the central bank reveals its target for inflation as well as its information on the demand shock, firms can therefore understand the reason behind the instrument's setting and then have more information about the mark-up shock, as they can perfectly infer the central bank's signal on it.
} 
target. By announcing its current target for inflation, the central bank provides firms with a focal point in their backward looking expectations, by indicating the extent to which they should be backward looking. Consequently, the central bank can easily deal with the underlying price dispersion towards its target due to the overreaction effect on the mark-up shock, without increasing too strongly its instrument. 


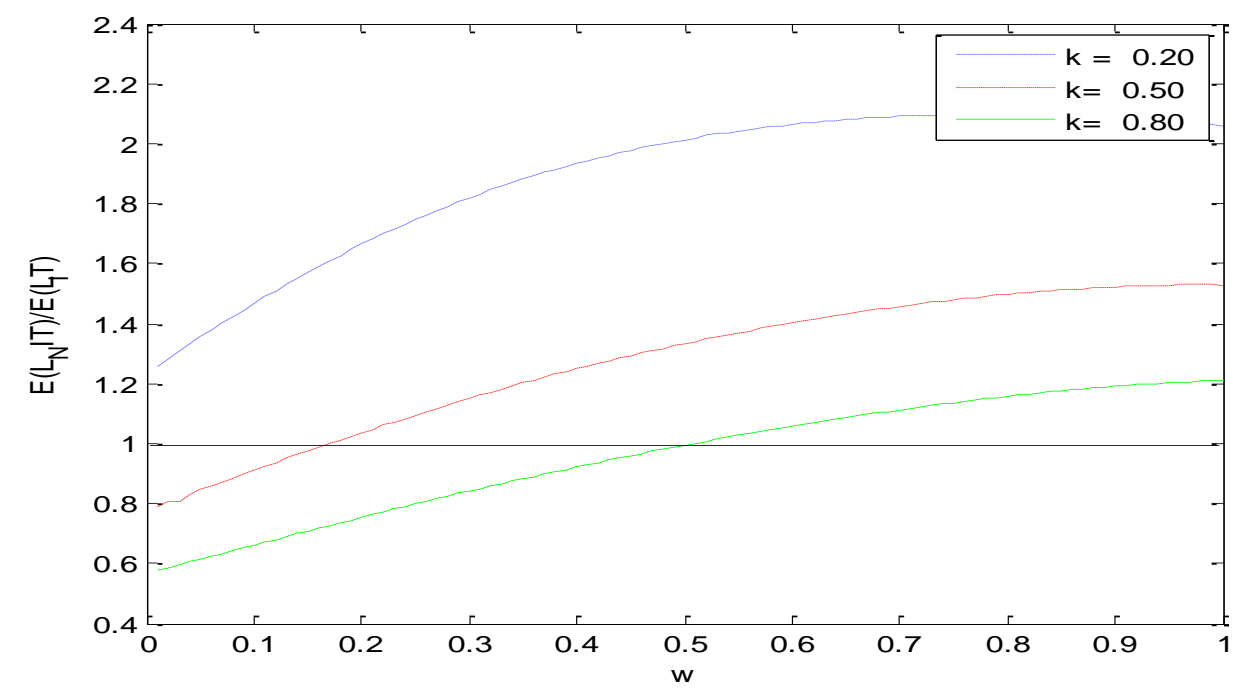

Figure 1: The ratio $\frac{E\left(L_{N I T}\right)}{E\left(L_{I T}\right)}$ as a function of price stickiness

\subsubsection{Optimal policy as a function of the precision of firms's private infor- mation}

Figure 2 presents the ratio as a function of the precision of firms's private information about the mark-up shock for three values of price stickiness. The remaining parameters values are : $\sigma_{u}^{2}=1, \sigma_{v}^{2}=1, \sigma_{\rho}^{2}=1, \sigma_{\varepsilon}^{2}=0.2, k=0.2, \sigma_{s}^{2}=0.2, \beta=0.99, \pi^{*}=2$, and $\lambda=0.3$. 


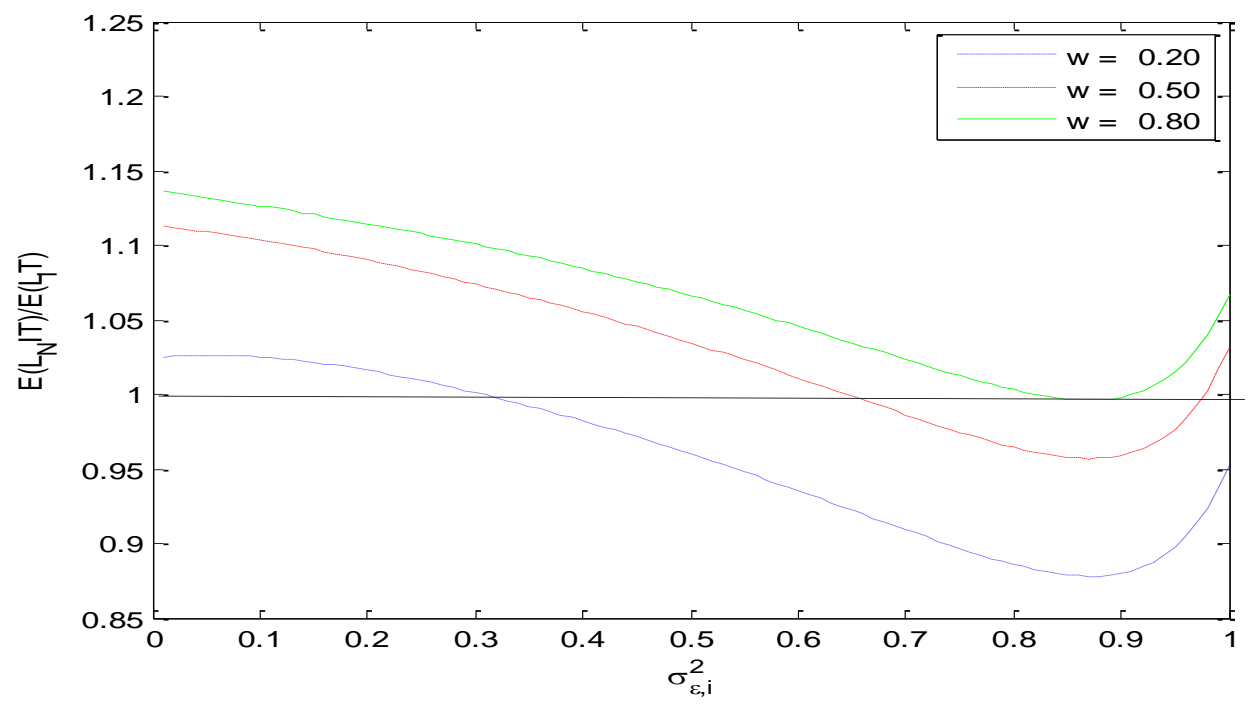

Figure 2: The ratio $\frac{E\left(L_{N I T}\right)}{E\left(L_{I T}\right)}$ as a function of the precision of firms's information on the mark-up shock

The figure again shows that when the degree of price stickiness is very high $(w=0.8)$, the monetary authority should explicitly adopt a target for inflation with respect to firms' information. By contrast, when prices are flexible enough $(w=0.2)$, the optimal choice depends on the precision of firms' private information about the mark-up shock. When firms have access to relatively precise information on the mark-up shock, the announcement of the target and the central bank's signal on the demand shock will not lead to overreaction of firms to the mark-up shock even in the case of high strategic complementarities, because firms already have precise information on it. They only focus on the central bank's target, and as their information about the fundamental is quite precise, expectations will quickly match the target. 


\subsubsection{Optimal policy as a function of the precision of central bank's informa- tion}

We now present the result according to the precision of central bank's information about the mark-up shock. Figure 3 presents this result for three values of price stickiness, and the following values of other parameters : $\sigma_{u}^{2}=1, \sigma_{v}^{2}=1, \sigma_{\rho}^{2}=1, \sigma_{\varepsilon i}^{2}=0.4, k=0.7$, $\sigma_{s}^{2}=0.2, \beta=0.99, \pi^{*}=2$, and $\lambda=0.3$.

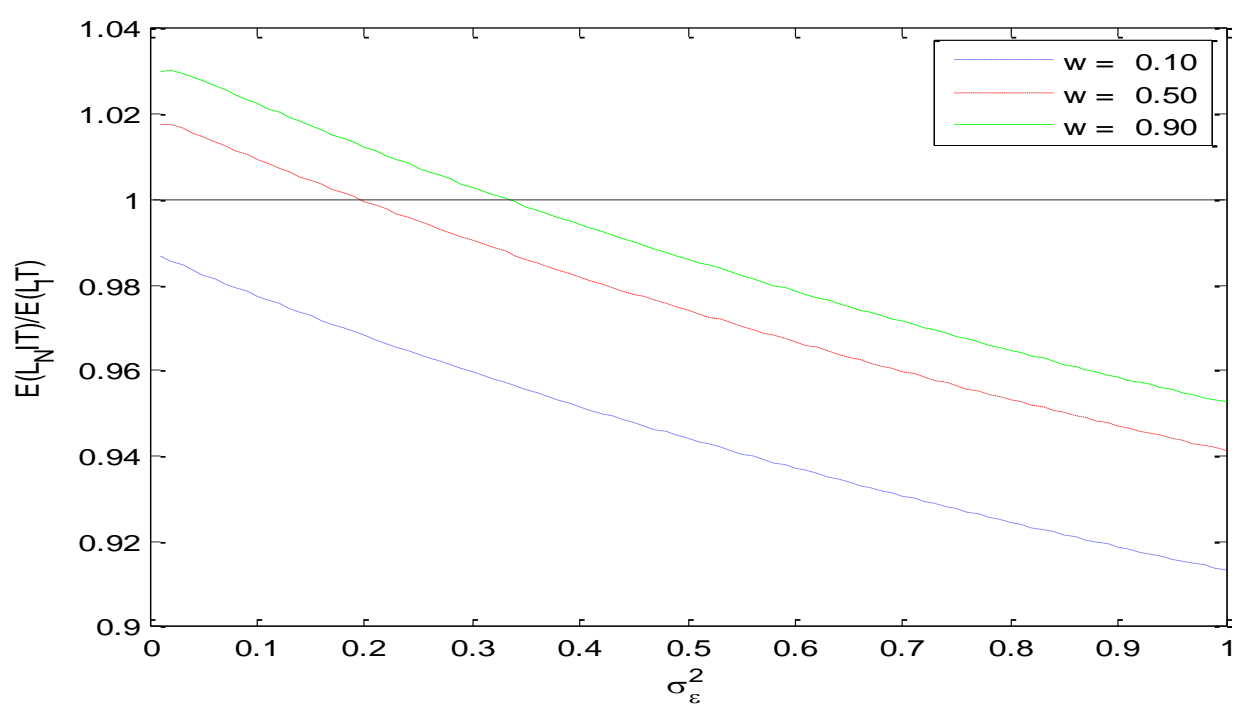

Figure 3: The ratio $\frac{E\left(L_{N I T}\right)}{E\left(L_{I T}\right)}$ as a function of the precision of central bank's information on the mark-up shock

The figure shows that when prices are very flexible $(w=0.1)$, adopting an inflation target is never optimal with respect to the precision of central bank's information on the mark-up shock. The analysis presented above stresses the importance of price stickiness, as well as both "overreaction effect" and "anchoring effect" of the target in the choice of inflation targeting. However, even in the case of high price stickiness $(w=0.9)$, the optimal policy will depend on the precision of central bank's information about the markup shock. Indeed, when central bank's information is too imprecise, inflation targeting 
may be harmful to social welfare. The detrimental consequences of the overreaction effect of adjusting firms to mark-up shock, dominates the positive impact of the target's anchoring effect. Conversely, when central bank's information about the mark-up shock is quite precise, explicitly adopting a target for inflation would be optimal as it bears the potentially negative impact of the overreaction effect. With more accurate central bank's information about the mark-up shock, firms' reaction to the mark-up shock stemming from explicit announcement, will no longer hamper social welfare, and therefore forecasts errors are limited.

\section{Concluding remarks}

In this paper, we theoretically analyze under what conditions should a central bank adopt an inflation targeting regime. to this end, we use a new keynesian's sticky prices framework à la Calvo [5], when the economy is characterized by heterogeneous information among firms and strategic complementarities in price setting. The main contribution of this paper is to highlight two key points in assessing our issue.

First, adopting an inflation targeting strategy depends on the sequential, but complementary importance of the different parameters of the model.

The analysis stresses that the degree of strategic complementarities is the first driving force in the choice of an optimal monetary policy. When strategic complementarities are low, the central bank must adopt an inflation targeting regime as a framework for its monetary policy, regardless the values of other parameters in the economy. By contrast, when strategic complementarities are quite strong, optimal policy in that case mainly depends on the degree of price stickiness, followed by the relevance of the central bank's information about the fundamentals of the economy.

Two main effects arise from this situation namely, the "overreaction effect" to mark-up shocks, and the "anchoring effect" of the inflation target. When prices are very flexible, it is never optimal for the central bank to be an inflation targeter, because the overreaction effect of firms' adjustment to mark-up shock dominates the target's anchoring effect. This overreaction effect to the mark-up shock amplifies firms reaction and as this shock cannot be offset by the central bank, that hampers social welfare. Conversely when prices are 
strongly sticky, the anchoring effect of the target dominates the overreaction effect to the mark-up shock and in the case where central bank's information is relatively precise, then adopting a target for inflation is optimal for monetary policy.

The second underlying key point is that, disseminating public information is essential but not sufficient for assessing the positive impact of inflation targeting regime. The information provided should be as accurate as possible, and this requires considerable efforts in modeling and forecasting macroeconomic data. So, the main question to be asked in assessing the positive effects of inflation targeting and hence transparency, is not knowing to what extent public information has to be supplied, but rather how accurate is this provided information. We then argue that, inflation targeting central banks must make greater efforts in their macroeconomic forecasts analysis, in order to be more efficient and to keep inflation targeting as the best practice in modern monetary policy. 


\section{A Appendix}

\section{A.1 Linear equilibrium and signal extraction under non-inflation targeting}

We depart from the optimal decision of adjusting firm $i$ given by :

$$
\pi_{i, t}^{*}=k(1-\omega) E_{i, t} \bar{\pi}_{t}^{*}+(1-\beta \omega) E_{i, t}\left[(1-k) d_{t}+u_{t}\right]+\left(\frac{\beta \omega}{1-\omega}\right) E_{i, t} \pi_{t+1} .
$$

Remember that the nominal aggregate output is defined as :

$$
d_{t}=I+v_{t}
$$

By replacing this into the equation above, one obtains:

$$
\pi_{i, t}^{*}=k(1-\omega) E_{i, t} \bar{\pi}_{t}^{*}+(1-\beta \omega) E_{i, t}\left[(1-k)\left(I+v_{t}\right)+u_{t}\right]+\left(\frac{\beta \omega}{1-\omega}\right) E_{i, t} \pi_{t+1} .
$$

The serially uncorrelated shocks' assumption implies that $E_{i, t} \pi_{t+1}=0$. We then postulate that the optimal choice facing adjusting firm $i$ is a linear combination of its private signal on the mark-up shock, as well as the observed monetary instrument :

$$
\pi_{i, t}^{*}=\gamma_{1} u_{i, t}+\gamma_{2} I
$$

The optimal weights $\gamma_{1}$ and $\gamma_{2}$ depend on firms' expectations about the pricing behavior of other adjusting firms. The conditional estimate of the average inflation by firm $i$ is therefore given by:

$$
E_{i, t}\left(\bar{\pi}_{t}^{*}\right)=\gamma_{1} E_{i}\left(u_{t}\right)+\gamma_{2} I
$$

Plugging this into (29) yields :

$$
\pi_{i, t}^{*}=k(1-\omega)\left(\gamma_{1} E_{i}\left(u_{t}\right)+\gamma_{2} I\right)+(1-\beta \omega) E_{i, t}\left[(1-k)\left(I+v_{t}\right)+u_{t}\right] .
$$

Otherwise, firm $i$ estimates the real realization of the mark-up and demand shocks as well as central bank's target for inflation, conditional on its two signals. This signal extraction is expressed as :

$$
E_{i}\left(\begin{array}{c}
u_{t} \\
v_{t} \\
\pi_{1} \\
\pi_{2}
\end{array}\right)=O\left(\begin{array}{c}
u_{i, t} \\
I
\end{array}\right)
$$


where $O=V_{\text {ou }} V_{o_{o}}^{-1}$ is a $4 \times 2$ matrix . $V_{\text {ou }}$ denotes the covariance matrix between the observed signals $\left[u_{i t}, I\right]$ and the unobserved variables $\left[u_{t}, v_{t}, \pi_{1}, \pi_{2}\right]$, and $V_{o o}$ is the covariance matrix between the observed signals themselves. Signal extraction then gives

$$
\begin{aligned}
& E_{i}\left(u_{t}\right)=O_{11} u_{i, t}+O_{12}\left(I-\alpha_{3} \pi^{*}\right), \\
& E_{i}\left(v_{t}\right)=O_{21} u_{i, t}+O_{22}\left(I-\alpha_{3} \pi^{*}\right), \\
& E_{i}\left(\pi_{1}\right)=O_{31} u_{i, t}+O_{32}\left(I-\alpha_{3} \pi^{*}\right), \\
& E_{i}\left(\pi_{2}\right)=O_{41} u_{i, t}+O_{42}\left(I-\alpha_{3} \pi^{*}\right) .
\end{aligned}
$$

Substituting $E_{i}\left(u_{t}\right)$ and $E_{i}\left(v_{t}\right)$ by their values in (31) yields :

$$
\begin{aligned}
\pi_{i, t}^{*}= & k(1-\omega)\left(\gamma_{1}\left(O_{11} u_{i, t}+O_{12}\left(I-\alpha_{3} \pi^{*}\right)\right)+\gamma_{2} I\right)+(1-\beta \omega)(1-k) I \\
& +(1-\beta \omega)(1-k)\left(O_{21} u_{i, t}+O_{22}\left(I-\alpha_{3} \pi^{*}\right)\right)+(1-\beta \omega)\left(O_{11} u_{i, t}+O_{12}\left(I-\alpha_{3} \pi^{*}\right)\right) .
\end{aligned}
$$

Collecting the same elements and equating the coefficients with those in (30) gives after some manipulations :

$$
\gamma_{1}=\frac{(1-\omega \beta)\left[(1-k) O_{21}+O_{11}\right]}{1-k(1-\omega) O_{11}}
$$

and

$$
\gamma_{2}=\frac{-(1-\omega \beta)(1-k)-\left(1-\alpha_{3} \pi^{*}\right)\left[(1-\omega \beta)\left((1-k) O_{22}+O_{12}\right)+k O_{12} \gamma_{1}(1-\omega)\right]}{k(1-\omega)-1} .
$$

By aggregating over all adjusting firms, it follows that :

$$
\overline{\pi_{t}^{*}}=\gamma_{1} u_{t}+\gamma_{2} I
$$

Letting $\tilde{\gamma}_{1}=(1-\omega) \gamma_{1}$ and $\tilde{\gamma}_{2}=(1-\omega) \gamma_{2}$, one therefore obtains the current aggregate inflation rate :

$$
\pi_{t}=(1-\omega) \overline{\pi_{t}^{*}}=\tilde{\gamma_{1}} u_{t}+\tilde{\gamma_{2}} I
$$

\section{A.2 Linear equilibrium and signal extraction under inflation targeting}

We still depart from the optimal decision of firm $i$ and follow the same process as before :

$$
\pi_{i, t}^{*}=k(1-\omega) E_{i, t}\left(\bar{\pi}_{t}^{*}\right)+(1-\beta \omega) E_{i, t}\left[(1-k)\left(I+v_{t}\right)+u_{t}\right] .
$$


The equilibrium strategy of firm $i$ is in this case a linear combination of its private signal on mark-up shock, the central bank's signal on demand shock, the target for inflation as well as the policy instrument :

$$
\pi_{i, t}^{*}=b_{1} u_{i, t}+b_{2} v_{c b, t}+b_{3} \pi_{2}+b_{4} I \text {. }
$$

The optimal weights $b_{1}, b_{2}, b_{3}$ and $b_{4}$ depend on firms' expectations about the pricing behavior of other adjusting firms. The conditional estimate of the average inflation by firm $i$ is therefore given by :

$$
E_{i, t}\left(\overline{\pi_{t}^{*}}\right)=b_{1} E_{i}\left(u_{t}\right)+b_{2} v_{c b}+b_{3} \pi_{2}+b_{4} I
$$

Plugging this into equation (32) yields :

$$
\pi_{i, t}^{*}=k(1-\omega)\left(b_{1} E_{i}\left(u_{t}\right)+b_{2} v_{c b}+b_{3} \pi_{2}+b_{4} I\right)+(1-\beta \omega) E_{i, t}\left[(1-k)\left(I+v_{t}\right)+u_{t}\right] .
$$

As the central bank announces explicitly its target to firms, they no longer need to infer this target. So, $E_{i}\left(\pi_{1}\right)=\pi_{1}$ and $E_{i}\left(\pi_{2}\right)=\pi_{2}$. Therefore, firm $i$ only estimates the real values of mark-up and demand shocks conditional on its received signals. This signal extraction is given by :

$$
E_{i}\left(\begin{array}{c}
u_{t} \\
v_{t}
\end{array}\right)=\Gamma\left(\begin{array}{c}
u_{i, t} \\
v_{c b} \\
\pi_{2} \\
I
\end{array}\right),
$$

where $\Gamma=\Lambda_{o u} \Lambda_{o}^{-1}$ is a $2 \times 4$ matrix. As before, $\Lambda_{o u}$ represents the covariance matrix between the observed signals and the unobserved variables, and $\Lambda_{o o}$ is the covariance matrix between the observed signals themselves. It follows from signal extraction that :

$$
\begin{aligned}
& E_{i}\left(u_{t}\right)=\Gamma_{11} u_{i, t}+\Gamma_{12} v_{c b}+\Gamma_{13}\left(\pi_{2}-\pi^{*}\right)+\Gamma_{14}\left(I-\alpha_{3} \pi^{*}\right), \\
& E_{i}\left(v_{t}\right)=\Gamma_{21} u_{i, t}+\Gamma_{22} v_{c b}+\Gamma_{23}\left(\pi_{2}-\pi^{*}\right)+\Gamma_{24}\left(I-\alpha_{3} \pi^{*}\right) .
\end{aligned}
$$

Replacing $E_{i}\left(u_{t}\right)$ and $E_{i}\left(v_{t}\right)$ by their values into (34) yields :

$$
\begin{aligned}
\pi_{i, t}^{*}= & k(1-\omega)\left(b_{1}\left(\Gamma_{11} u_{i, t}+\Gamma_{12} v_{c b}+\Gamma_{13}\left(\pi_{2}-\pi^{*}\right)+\Gamma_{14}\left(I-\alpha_{3} \pi^{*}\right)\right)+b_{2} v_{c b}+b_{3} \pi_{2}+b_{4} I\right) \\
& +(1-\beta \omega)(1-k) I+(1-\beta \omega)(1-k)\left(\Gamma_{21} u_{i, t}+\Gamma_{22} v_{c b}+\Gamma_{23}\left(\pi_{2}-\pi^{*}\right)+\Gamma_{24}\left(I-\alpha_{3} \pi^{*}\right)\right) \\
& +(1-\beta \omega)\left(\Gamma_{11} u_{i, t}+\Gamma_{12} v_{c b}+\Gamma_{13}\left(\pi_{2}-\pi^{*}\right)+\Gamma_{14}\left(I-\alpha_{3} \pi^{*}\right)\right) .
\end{aligned}
$$


Collecting the same elements and equating coefficients with those in (33) gives :

$$
\begin{gathered}
b_{1}=\frac{(1-\omega \beta)\left[(1-k) \Gamma_{21}+\Gamma_{11}\right]}{1-k(1-\omega) \Gamma_{11}}, \\
b_{2}=\frac{-(1-\omega \beta)\left[(1-k) \Gamma_{22}+\Gamma_{12}\right]-k b_{1}(1-\omega) \Gamma_{12}}{k(1-\omega)-1}, \\
b_{3}=\frac{-\left(1-\pi^{*}\right)\left[(1-\omega \beta)\left((1-k) \Gamma_{23}+\Gamma_{13}\right)+k b_{1}(1-\omega) \Gamma_{13}\right]}{k(1-\omega)-1}, \\
b_{4}=\frac{-(1-\omega \beta)(1-k)-\left(1-\alpha_{3} \pi^{*}\right)\left[(1-\omega \beta)\left((1-k) \Gamma_{24}+\Gamma_{14}\right)+k b_{1}(1-\omega) \Gamma_{14}\right]}{k(1-\omega)-1} .
\end{gathered}
$$

By aggregating over all adjusting firms, it follows that :

$$
\overline{\pi_{t}^{*}}=b_{1} u_{t}+b_{2} v_{c b}+b_{3} \pi_{2}+b_{4} I
$$

Letting $\overline{b_{1}}=(1-\omega) b_{1}, \overline{b_{2}}=(1-\omega) b_{2}, \overline{b_{3}}=(1-\omega) b_{3}$ and $\overline{b_{4}}=(1-\omega) b_{4}$, one hence obtains the current aggregate inflation rate :

$$
\pi_{t}=(1-\omega) \overline{\pi_{t}^{*}}=\overline{b_{1}} u_{t}+\overline{b_{2}} v_{c b}+\overline{b_{3}} \pi_{2}+\overline{b_{4}} I
$$

\section{References}

[1] George-Marios Angeletos and Jennifer La'O. Incomplete information, higher-order beliefs and price inertia. Journal of Monetary Economics, 56(Supplement 1):S19 S37, 2009.

[2] Romain Baeriswyl and Camille Cornand. The signaling role of policy actions. Journal of Monetary Economics, 57(6):682 - 695, 2010.

[3] R.J. Barro and D.B. Gordon. A positive theory of monetary policy in a natural rate model. Journal of Political Economy, 91:589-610, 1983.

[4] Mark Bils and Pete Klenow. Some evidence on the importance of sticky prices. Journal of Political Economy, 112:947-985, 2004. 
[5] Guillermo Calvo. Staggered prices in a utility maximizing framework. Journal of Monetary Economics, 12:383-398, 1983.

[6] Maria Demertzis and Andrew Hughes Hallett. Central bank transparency in theory and practice. Journal of Macroeconomics, 29(4):760-789, 2007.

[7] Maria Demertzis and Nicola Viegi. Inflation targets as focal points. International Journal of Central Banking, 4(1):55-87, March 2008.

[8] Maria Demertzis and Nicola Viegi. Inflation targeting : a framework for communication. The B.E. Journal of Macroeconomics, 9, 2009.

[9] Benjamin Friedman and Kennett Kuttner. A price target for u.s. monetary policy? lessons from the experience with money growth targets. Brookings Papers on Economic Activity, 1:77-146, 1996.

[10] Petra Maria Geraats. Central bank transparency. Economic Journal, 112(483):532$565,2002$.

[11] Petra Maria Geraats. Trends in monetary policy transparency. International Finance, 12(2):235-268, 2009.

[12] Christian Hellwig. Heterogeneous information and the welfare effects of public information disclosures. Technical report, UCLA mimeo, 2005.

[13] Jonathan James and Phillip Lawler. Optimal policy intervention and the social value of public information. American Economic Review, 101(4):1561-74, june 2011.

[14] M. King. The inflation target five years on. Bank of England Quaterly Bulletin, 37:434-442, 1997.

[15] A.T. Levin, F.M. Natalucci, and J.M. Piger. The macroeconomic effects of inflation targeting. Federal Reserve Bank of St. Louis Review, 86(4):51-80, 2004.

[16] Robert E. Lucas. Expectations and the neutrality of money. Journal of Economic Theory, 4(2):103-124, 1972. 
[17] Stephen Morris and Hyun Song Shin. Social value of public information. American Economic Review, 92(5):1521-1534, December 2002.

[18] Edmund Phelps. Introduction: The New Microeconomics in Employment and Inflation Theory, chapter In : Microeconomic Foundations of Employment and Inflation Theory. New York : Norton, 1970.

[19] Mauro Roca. Transparency and monetary policy with imperfect common knowledge. Technical report, IMF working paper No. 10/91., 2010.

[20] S. Roger and M. Stone. On target? the international experience with achieving inflation targets. Technical report, IMF working paper No. 05/163., 2005.

[21] Jon Steinsson. Optimal monetary policy in an economy with inflation persistence. Journal of Monetary Economics, 50(7):1425-1456, October 2003.

[22] Lars E. O. Svensson. Inflation targeting: Should it be modeled as an instrument rule or a targeting rule? European Economic Review, 46(4-5):771-780, May 2002.

[23] Lars E.O. Svensson. Optimal inflation targets, 'conservative' central banks, and linear inflation contracts. American Economic Review, 87:98-114, 1997.

[24] Lars E.O. Svensson. The social value of information: Morris and shin (2002) is actually pro transparency, not con. American Economic Review, 96:448-451, 2006.

[25] Lars E.O. Svensson. Inflation Targeting, chapter in The New Palgrave Dictionary of Economics. 2nd edition, May 2007.

[26] John Taylor. Aggregate dynamics and staggered contracts. Journal of Political Economy, 88(1):1-23, 1980.

[27] Carl Walsh. Optimal economic transparency. International Journal of Central Banking, 3:5-36, 2007.

[28] Carl Walsh. Transparency, Flexibility and Inflation Targeting, chapter In : Monetary Policy under Inflation Targeting, pages 227-263. Santiago, Chile, Santiago, Chile, 2007. 
[29] Michael Woodford. Inflation stabilization and welfare. Working Paper 8071, National Bureau of Economic Research, January 2001.

[30] Michael Woodford. Central bank communication and policy effectiveness. Working Paper 11898, National Bureau of Economic Research, December 2005. 